$\begin{array}{lll}\text { Guramrinder Singh Thind, MD } & \text { Steven Fox, MD } & \text { Mohit Gupta, MD } \\ \text { Department of Critical Care Medicine, } & \text { Department of Critical Care Medicine, } & \text { Department of Hospital Medicine, Cleveland Clinic, } \\ \text { Respiratory Institute, Cleveland Clinic, } & \text { Respiratory Institute, Cleveland Clinic, } & \text { Cleveland, OH; Clinical Assistant Professor, Cleveland } \\ \text { Cleveland, } \mathrm{OH} & \text { Cleveland, } \mathrm{OH} & \begin{array}{l}\text { Clinic Lerner College of Medicine of Case Western } \\ \text { Reserve University, Cleveland, } \mathrm{OH}\end{array}\end{array}$

Praveen Chahar, MD

Anesthesiology Institute, Cleveland Clinic Cleveland, OH; Clinical Assistant Professor, Cleveland Clinic Lerner College of Medicine of Case Western Reserve University, Cleveland, $\mathrm{OH}$
Robert Jones, DO, FACEP

Department of Emergency Medicine, Metro-

Health Medical Center, Cleveland, OH; Professor, Cleveland Clinic Lerner College of Medicine of Case Western Reserve University, Cleveland, $\mathrm{OH}$

\section{Siddharth Dugar, MD}

Department of Critical Care Medicine, Respiratory Institute, Cleveland Clinic, Cleveland, $\mathrm{OH}$; Clinical Assistant Professor, Cleveland Clinic Lerner College of Medicine of Case Western Reserve University, Cleveland, $\mathrm{OH}$

\title{
Point-of-care ultrasonography for the hospitalist
}

\section{ABSTRACT}

Point-of-care ultrasonography (POCUS) has emerged as a vital tool in medicine. Initially used for procedural guidance, POCUS is now used for diagnostics and monitoring of the lung, heart, abdomen, and deep vein thrombosis. This wide applicability makes it an essential tool for hospitalists in daily clinical practice. This article provides an overview of the clinical integration of POCUS and basic image interpretation.

\section{KEY POINTS}

Lung POCUS can help in evaluating pneumothorax, alveolar-interstitial syndrome, lung consolidation, and pleural effusions as the cause for respiratory distress.

Focused cardiac ultrasonography can help in evaluating left and right ventricular function, right atrial pressure, pericardial effusion, and tamponade.

Abdominal ultrasonography can aid evaluation of ascites, hemoperitoneum, hydronephrosis, acute pyelonephritis, and gallstones, and can confirm Foley catheter placement.

Point-of-care compression ultrasonography can rapidly detect deep vein thrombosis with high accuracy.

POCUS can guide numerous procedures, including central venous catheter insertion, peripheral intravenous catheter insertion, abdominal paracentesis, and thoracentesis.
TOSPItalists ARE INCREASINGLY USING 1 point-of-care ultrasonography (POCUS), and have access to ultrasound machines that are more portable, more available, and less expensive. The numerous uses of POCUS for procedural guidance, diagnosis, and monitoring can add considerable value to patient care.

All hospitalists should have an understanding of POCUS nomenclature, applications, and findings. This review highlights various uses of POCUS in hospitalized patients.

\section{DIRECT CLINICIAN INVOLVEMENT}

Ultrasonography is low-cost, radiation-free, and noninvasive, allowing it to be repeated multiple times with little risk to patients. What sets it apart from traditional diagnostic ultrasonography is that it is wholly performed by a bedside clinician directly involved in patient care, without requiring a sonographer and radiologist for image acquisition and interpretation (Table 1). A hospitalist can quickly perform a physical examination combined with goal-directed ultrasonography of various organs based on presenting signs and symptoms. Serial scans can be performed to assess progression or response to therapy.

POCUS enhances patient experience and patient-clinician rapport by increasing interactions between the clinician and patient. ${ }^{1}$ POCUS has become notably important in the COVID-19 pandemic, allowing protocolized ultrasonographic assessment of multiple organs by a bedside physician, thereby minimizing exposure and the need for formal studies. ${ }^{2}$

Recognizing the importance of POCUS, numerous medical schools have integrated training in ultrasonography in their curricula. 


\section{TABLE 1}

\section{Point-of-care ultrasonography workflow compared with traditional consultative ultrasonography}

\begin{tabular}{l|l|l} 
& $\begin{array}{l}\text { Consultative } \\
\text { ultrasonography }\end{array}$ & POCUS \\
\hline Decision to perform ultrasonography & Primary clinician & \\
\hline Image acquisition & Sonographer & \multirow{2}{*}{ Primary clinician } \\
\hline Image interpretation & $\begin{array}{l}\text { Sonographer } \\
\text { Radiologist }\end{array}$ & \\
\hline Clinical integration & $\begin{array}{l}\text { Radiologist } \\
\text { Primary clinician }\end{array}$ &
\end{tabular}

The Society of Hospital Medicine, the American College of Physicians, and the Alliance for Academic Internal Medicine, have also endorsed its use..$^{3-5}$

Billing for ultrasound-assisted procedures may provide a means to offset the costs of equipment, training, and administration.

\section{IMPROPER USE AND INTERPRETATION CAN CAUSE HARM}

POCUS can improve patient care but may

The absence of lung sliding should prompt the search for 'lung point,' which is virtually pathognomonic for pneumothorax also cause harm through improper use and interpretation. ${ }^{6}$ It needs to be applied in a deliberate and thoughtful manner: multiple views should be obtained for appropriate interpretation, and images must be evaluated in the clinical context. A comprehensive imaging study should be considered if POCUS was of limited utility and the probability of a particular disorder remains high despite negative findings with POCUS.

The accuracy of POCUS depends on the skills and judgment of the operator. Even if basic findings are understood, many nuances and potential pitfalls exist. Clinicians may be falsely reassured by seemingly normal POCUS findings while the patient actually has a serious disease that a radiologic study could detect. Conversely, incidental findings may lead to unnecessary treatments and testing.

But because POCUS may be used improperly does not mean it should not be used. In fact, the major medicolegal issue surrounding POCUS is failure to perform it in a timely fashion. $^{\text {? }}$

\section{LUNG AND PLEURAL ULTRASONOGRAPHY}

Lung and pleural ultrasonography can narrow the broad differential diagnosis of respiratory distress (Table 2) ${ }^{8-11}$ and facilitate prompt management. ${ }^{12}$ In many hospitals, no radiologist is available to perform lung ultrasonography, making lung and pleural POCUS a critical skill for hospitalists. Training in lung and pleural POCUS is feasible with a simple curriculum consisting of didactics and limited supervised examinations. ${ }^{13,14}$

\section{Initial lung assessment}

Lung assessment starts with identifying the pleural line, a shimmering hyperechoic structure between the ribs (Figure 1). Respirophasic sliding of the pleura gives a shimmering appearance, referred to as "lung sliding."

The tissue-air interface in the subpleural region of aerated lung is a strong reflector. Ultrasound is repeatedly reflected between the pleura and the probe, leading to a reverberation artifact appearing as equidistant parallel echoic lines, known as A lines (Figure 1). An A-line pattern indicates normal lung, but it can also be seen with pneumothorax and in conditions with normally aerated pulmonary parenchyma, such as pulmonary embolism, chronic obstructive pulmonary disease, and asthma. ${ }^{15}$

\section{Evaluation of pneumothorax}

In pneumothorax, the air between the parietal and visceral pleurae prevents pleural contact, giving an A-line pattern without lung sliding. Absence of lung sliding has good sensitivity (>95\%) for pneumothorax but poor specificity $(60 \%-99 \%) .8,16$ This pattern also occurs 
TABLE 2

\begin{tabular}{|c|c|c|c|c|c|c|c|c|c|}
\hline Diagnosis & Meta-analysis & $\begin{array}{l}\text { No. of } \\
\text { studies }\end{array}$ & $\begin{array}{l}\text { No. of } \\
\text { patients }\end{array}$ & $\begin{array}{l}\text { Pooled } \\
\text { sensitivity }\end{array}$ & $\begin{array}{l}95 \% \\
\text { confidence } \\
\text { interval }\end{array}$ & $\begin{array}{l}\text { Pooled } \\
\text { specificity }\end{array}$ & $\begin{array}{l}95 \% \\
\text { confidence } \\
\text { interval }\end{array}$ & $\begin{array}{l}\text { Positive } \\
\text { likelihood } \\
\text { ratio }\end{array}$ & $\begin{array}{l}\text { Negative } \\
\text { likelihood } \\
\text { ratio }\end{array}$ \\
\hline $\begin{array}{l}\text { Pleural } \\
\text { effusion }\end{array}$ & $\begin{array}{l}\text { Yousefifard et al, } \\
2016\end{array}$ & 12 & 1,554 & $94 \%$ & $88 \%-97 \%$ & $98 \%$ & $92 \%-100 \%$ & 53.96 & 0.06 \\
\hline $\begin{array}{l}\text { Acute } \\
\text { cardiogenic } \\
\text { pulmonary } \\
\text { edema }\end{array}$ & $\begin{array}{l}\text { Maw et al, }{ }^{9} \\
2019\end{array}$ & 7 & 1,075 & $94.1 \%$ & $\begin{array}{l}81.3 \%- \\
98.3 \%\end{array}$ & $92.4 \%$ & $\begin{array}{l}84.2 \%- \\
96.4 \%\end{array}$ & 12.38 & 0.06 \\
\hline Pneumonia & $\begin{array}{l}\text { Alzahrani et al, }{ }^{10} \\
2017\end{array}$ & 20 & 2,513 & $85 \%$ & $84 \%-87 \%$ & $93 \%$ & $92 \%-95 \%$ & 12.14 & 0.16 \\
\hline $\begin{array}{l}\text { Pneumo- } \\
\text { thorax }\end{array}$ & $\begin{array}{l}\text { Alrajab et al, } \\
2013^{\text {a }}\end{array}$ & 13 & 1,514 & $78.6 \%$ & $\begin{array}{l}68.1 \%- \\
98.1 \%\end{array}$ & $98.4 \%$ & $\begin{array}{l}97.3 \%- \\
99.5 \%\end{array}$ & 49.13 & 0.22 \\
\hline
\end{tabular}

a Included 1 study that used lung sliding sign alone, 12 studies that used lung sliding and comet tail signs, and 6 studies that included lung point in addition to the other 2 signs.

with pleural adhesions, apnea, pneumonia, and right mainstem bronchus intubation. ${ }^{16,17}$ The absence of lung sliding should prompt the search for "lung point," ie, the transition point at the edge of the pneumothorax where lung sliding is seen in one part and no lung sliding is seen in the rest. Lung point is virtually pathognomonic for pneumothorax (Video 1). ${ }^{17}$

Unlike lung point, absent lung sliding is not specific for pneumothorax and should not by itself prompt tube thoracostomy in the absence of extenuating circumstances (eg, severe cardiorespiratory instability, high clinical suspicion).

\section{Evaluation of alveolar-interstitial syndrome}

The pathologies of alveolar-interstitial space are characterized by B lines, a sonographic pattern of vertically oriented, laser-like hyperechoic artefacts originating at the pleural interface, extending downwards, and moving synchronously with the pleura (Figure 2). One or $2 \mathrm{~B}$ lines are routinely seen; 3 or more in a single field of view is considered abnormal. ${ }^{18-20}$ Any condition that leads to thickening of subpleural interlobular septa generates $\mathrm{B}$ lines, the most common being pulmonary edema (cardiogenic or noncardiogenic in origin).

The sensitivity of $\mathrm{B}$ lines in identifying pulmonary edema is at least $90 \%, 9,21,22$ making POCUS an excellent tool to differentiate car-

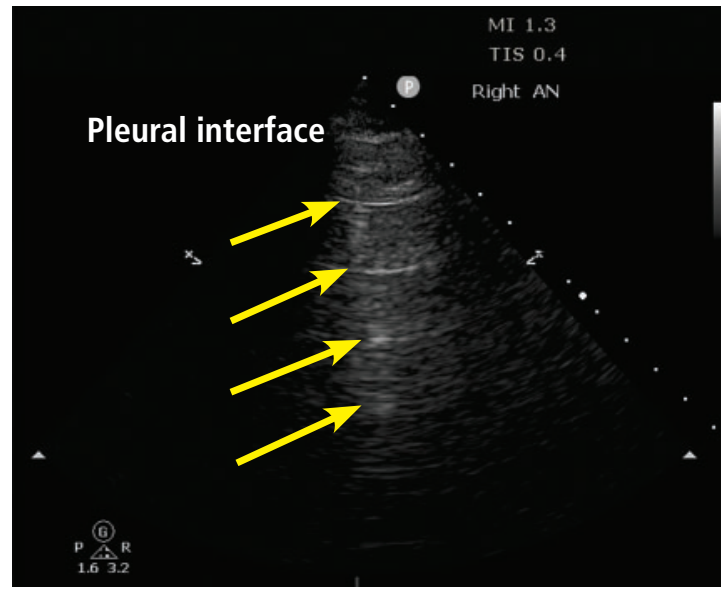

View videos for this article at ccjm.org

Figure 1. A lines. The A-line pattern occurs in normal lung and in pneumothorax. Ultrasound waves (arrows) reflect off the pleural interface repeatedly, producing repeated horizontal lines throughout the field.

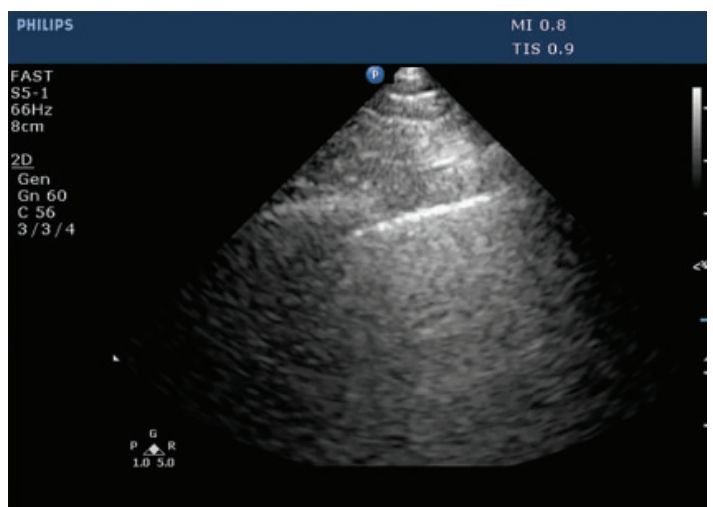

Video 1. Lung point. 


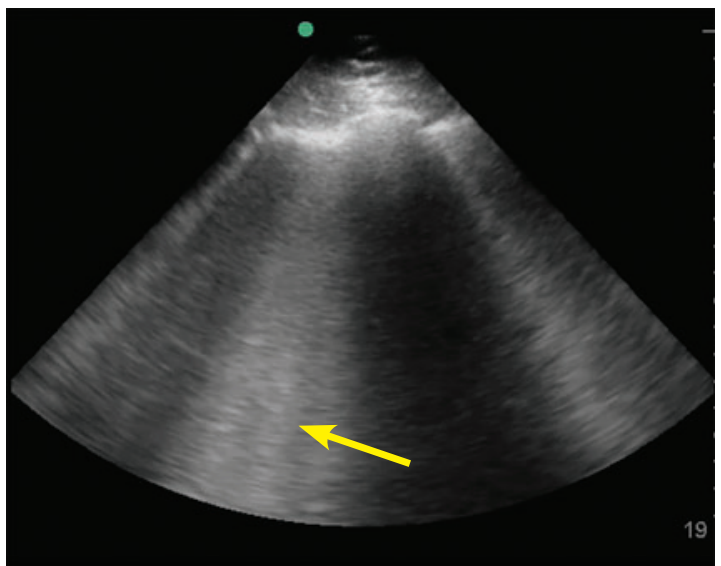

Figure 2. B lines. The B-line pattern occurs in the setting of interstitial thickening by any cause, including cardiogenic pulmonary edema, noncardiogenic pulmonary edema, interstitial fibrosis, and interstitial pneumonia/pneumonitis. It is analogous to groundglass opacity on computed tomography. It is demonstrated by vertical lines resembling the tail of a comet and extending to the bottom of the screen. In this image, confluent B lines (arrow) indicate significant interstitial involvement.

diogenic pulmonary edema from exacerbation

Focused cardiac ultrasonography provides critical insight into hemodynamic status of chronic obstructive pulmonary disease. In addition, B lines may help guide diuresis and assess fluid tolerance.

B lines also occur in pneumonia, pulmonary fibrosis, acute respiratory distress syndrome, and pneumonitis of any etiology. Careful evaluation of the pattern of B-line distribution and the pleural line, along with clinical correlation, can help distinguish these different causes (Table 3). ${ }^{23-25}$

The presence of $\mathrm{B}$ lines effectively rules out pneumothorax, as they are produced from subpleural lung units. ${ }^{17}$

\section{Evaluation of consolidation}

Ultrasound waves can traverse subpleural lung consolidation, resulting in the absence of $\mathrm{A}$ lines and a true 2-dimensional image of the consolidated lung (Figure 3). Almost all acute alveolar consolidations (98.5\%) are found adjoining the visceral pleura, providing the necessary window for detection. ${ }^{26}$

The finding of subpleural consolidation or focal B lines, or both, is suggestive of pneumonia. The sensitivity and specificity of lung

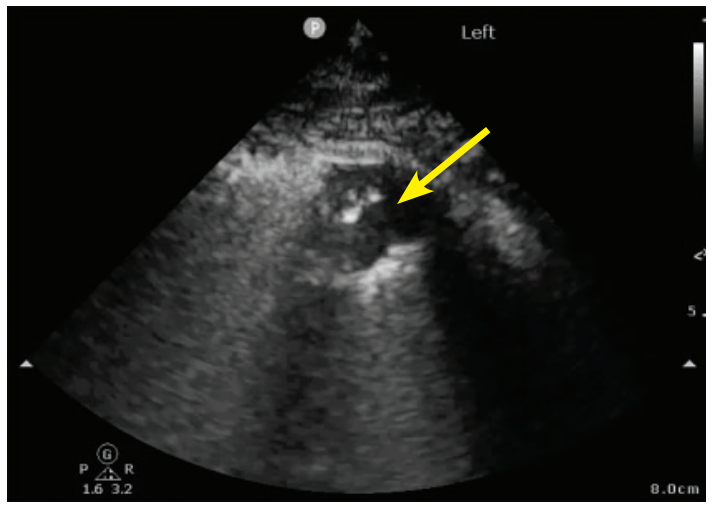

Figure 3. Small peripheral (subpleural) consolidation. This is demonstrated by a small area of lung parenchyma visualized directly beneath the pleura (arrow). This pattern is common in bacterial or viral pneumonia, including COVID-19 pneumonia.

ultrasonography for diagnosing pneumonia is just $85 \%$ or more. ${ }^{10}$ Nonetheless, supportive clinical and laboratory data with the characteristic ultrasound patterns can substantiate a diagnosis of pneumonia.

\section{Evaluation of pleural effusion}

Portable chest radiography has a sensitivity of $60 \%$ for detecting pleural effusion ${ }^{27}$; in contrast, lung ultrasonography is $94 \%$ sensitive and $98 \%$ specific. ${ }^{11}$ Lung ultrasonography can also better characterize basal opacities by distinguishing consolidation from pleural effusion (Figure 4). It can also detail the features of pleural effusion, with simple effusion appearing anechoic, and complex effusions characterized by septations, loculations, and debris. The size of a pleural effusion can also be quantified using lung ultrasonography. ${ }^{28}$

\section{FOCUSED CARDIAC ULTRASONOGRAPHY}

Focused cardiac ultrasonography (this term is preferred to "echocardiography" to highlight its focused nature) provides critical insight into hemodynamic status. It can be performed with excellent diagnostic accuracy for important cardiac abnormalities (Table 4). ${ }^{29}$

Focused questions, including global assessment of left ventricular function, presence or absence of a pericardial effusion, assessment of right ventricular size and function, and estimation of right atrial pressure, can help nar- 
TABLE 3

\section{Characteristics of B lines based on etiology a}

\begin{tabular}{|c|c|c|c|c|}
\hline & $\begin{array}{l}\text { Cardiogenic } \\
\text { pulmonary edema }\end{array}$ & $\begin{array}{l}\text { Noncardiogenic } \\
\text { diffuse pulmonary } \\
\text { interstitial edema }\end{array}$ & $\begin{array}{l}\text { Interstitial pneumonia } \\
\text { or pneumonitis } \\
\text { (bacterial, viral, } \\
\text { or inflammatory) }\end{array}$ & Interstitial fibrosis \\
\hline \multirow[t]{3}{*}{ Distribution } & Diffuse & Diffuse or patchy & Focal or patchy & Diffuse or patchy \\
\hline & $\begin{array}{l}\text { Usually bilateral } \\
\text { and symmetric }\end{array}$ & Often asymmetric & Usually asymmetric & Variable symmetry \\
\hline & $\begin{array}{l}\text { Predominant in } \\
\text { dependent regions }\end{array}$ & & & \\
\hline Spared areas & Absent & Often present & Present & Often present \\
\hline $\begin{array}{l}\text { Number } \\
\text { of B lines }\end{array}$ & Variable & Variable & Variable & Variable \\
\hline Pleura & Smooth & Irregular & Irregular & Irregular \\
\hline $\begin{array}{l}\text { Subpleural } \\
\text { consolidations }\end{array}$ & Absent & Present & Present & Typically absent \\
\hline $\begin{array}{l}\text { Reduced lung } \\
\text { sliding }\end{array}$ & Absent & May be present & May be present & May be present \\
\hline Pleural effusion & Often present & Typically absent & May be present & Typically absent \\
\hline
\end{tabular}

row a differential diagnosis and guide management in patients with cardiorespiratory distress.

\section{Evaluating left ventricular function}

Evaluation of left ventricular systolic function is one of the primary objectives of focused cardiac ultrasonography. As a general rule, multiple views should be obtained for appropriate interpretation. Although objective methods of left ventricular systolic evaluation are available and recommended, qualitative "eyeball estimation" is appropriate and feasible, with studies demonstrating high accuracy of visual estimation compared with recommended objective measures. ${ }^{30,31}$ Left ventricular systolic function can be qualitatively graded as severely reduced, moderately reduced, mildly reduced, normal, or hyperdynamic. Cardiologyperformed echocardiography can be requested for further quantitative evaluation (Video 2, Video 3).

\section{Evaluating right ventricular function}

Better understanding of the importance of right ventricular function has led to including

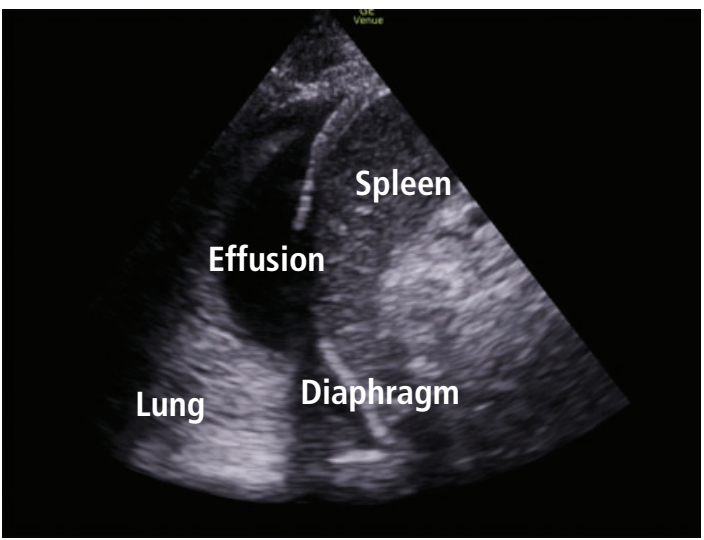

Evaluating
left ventricular
systolic function
is one of the
primary
objectives
of focused
cardiac ultra-
sonography

Figure 4. Pleural effusion and consolidation.

its evaluation in various protocols assessing shock and respiratory failure. ${ }^{32}$ Although objectively estimating right ventricular size and function is challenging, qualitative assessment can be made at the bedside by directly comparing the left and right ventricle.

Size. The right ventricle is normally less than two-thirds the size of the left. A right ventricle-to-left ventricle ratio of 1 or higher is associated with poor outcomes in pulmo- 
TABLE 4

\section{Focused cardiac ultrasonography: Basic views and key findings}

Views
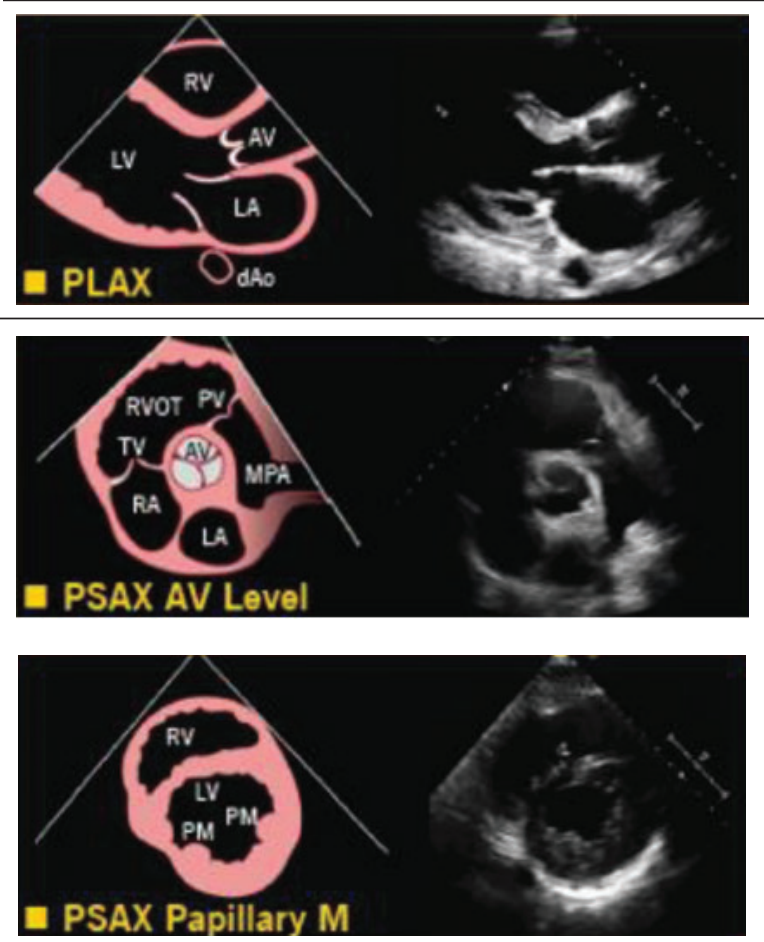

Probe position

Left 3rd to 5 th intercostal space

adjacent to the sternum, with

probe marker pointing toward

the right shoulder
Possible findings

Pericardial effusion

Signs of tamponade

Left ventricular size and systolic function

Mitral and aortic valvular pathology

Aortic root dissection

From the PLAX view, the probe is rotated $90^{\circ}$ clockwise. PSAX views are obtained by tilting the transducer from the base to the apex of the left ventricle.
Left ventricular systolic function

Tricuspid, aortic, and mitral valvular pathology

Interventricular septal deviation

Wall-motion abnormalities

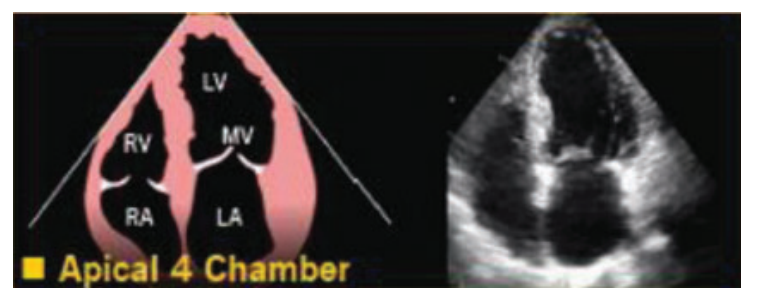

With the probe marker pointing toward the left, the probe is placed at the apex of the left ventricle. The apical impulse can be used as a guide.
Left ventricular size and function Right ventricular size and function Pericardial effusion and signs of tamponade

Valvular pathology Interventricular septal deviation Wall-motion abnormalities

Pericardial effusion and signs of tamponade

Inferior vena cava size and collapsibility
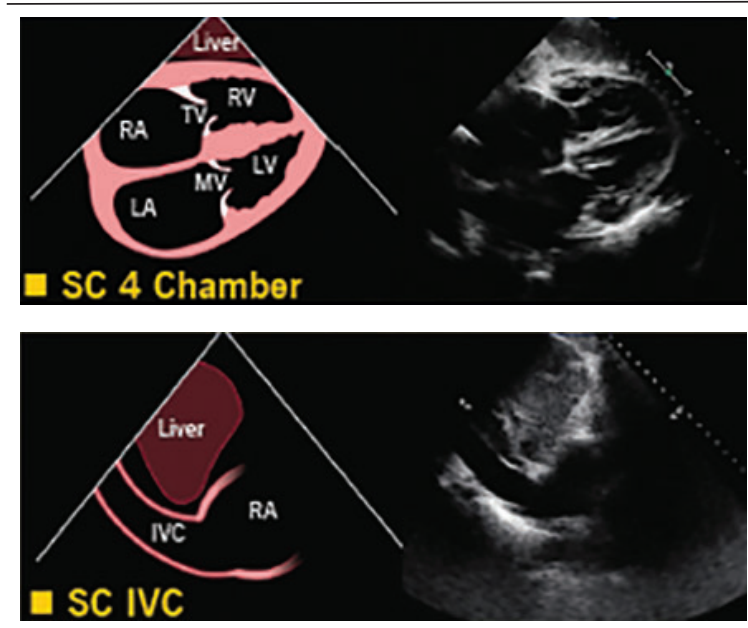

The probe is placed below the xiphoid process, with the marker pointing toward the left.

From the subcostal long-axis view, the probe is rotated $90^{\circ}$ counterclockwise and angulated slightly toward the left.

$\mathrm{AV}=$ aortic valve; IVC = inferior vena cava; $\mathrm{LV}=$ left ventricle; $\mathrm{MV}=$ mitral valve; $\mathrm{PLAX}=$ parasternal long axis; $\mathrm{PSAX}=$ parasternal short axis; $\mathrm{RV}=$ right ventricle; TV = tricuspid valve 


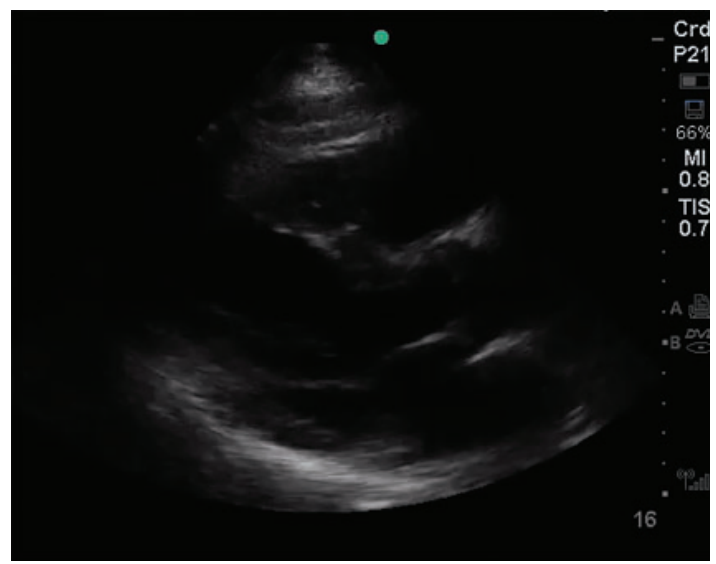

Video 2. Normal parasternal long axis view.

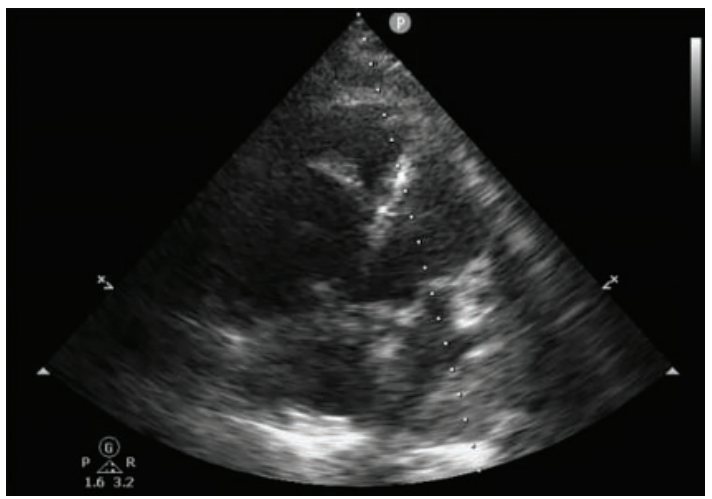

Video 4. Dilated right ventricle.

nary hypertension, pulmonary embolism, and other critical conditions.

Septal kinetics. Assessing septal kinetics can also provide vital insights and help identify the cause of right ventricular dysfunction: septal deviation occurs toward the left ventricle in diastole with right ventricular volume overload, and during systole with right ventricular pressure overload.

Chronicity. It is important to distinguish acute from chronic right ventricular dysfunction, as their causes differ. Distinguishing them is challenging with focused cardiac ultrasonography, yet certain subtle findings can point to the cause.

Chronic dysfunction is seen in long-standing cases of pulmonary hypertension. It is associated with right ventricular hypertrophy with right ventricular free-wall thickness of more than $5 \mathrm{~mm}$ (Video 4).

Acute dysfunction raises concern for massive pulmonary embolism, acute respiratory

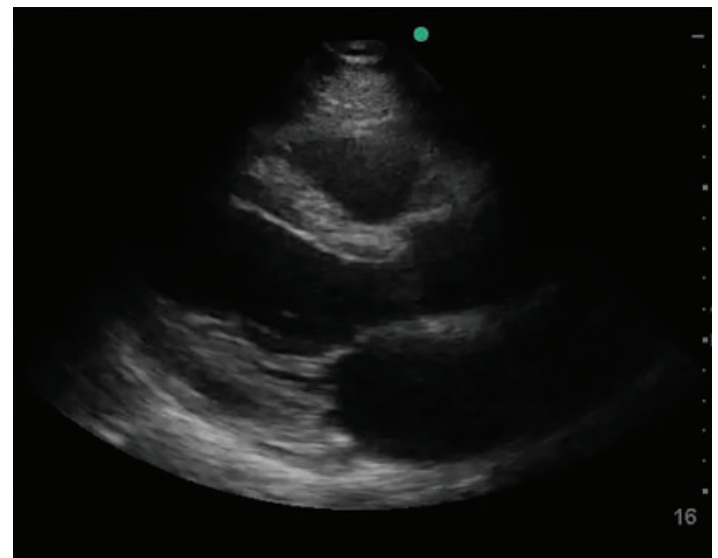

Video 3. Reduced ejection fraction.

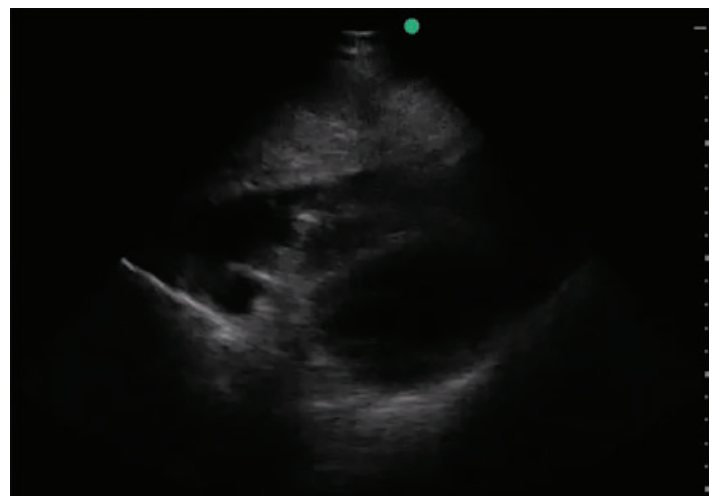

Video 5. Pericardial effusion and tamponade.

distress syndrome, and acute right ventricular infarction. In acute right ventricular dysfunction, particularly pulmonary embolism, the McConnell sign (ie, right ventricular freewall akinesis with sparing of the apex) is just $70 \%$ sensitive and $33 \%$ specific for diagnosing acute pulmonary embolism (positive likelihood ratio [PLR] 1.04, negative likelihood ratio [NLR] 0.91). ${ }^{33}$ Hence, pulmonary embolism cannot be definitively diagnosed with focused cardiac ultrasonography, with the notable exception of detecting a visible thrombus in the right heart (ie, a clot in transit).

\section{Evaluating valvular abnormalities}

Limited evaluation of the mitral, tricuspid, and aortic valves can be performed using standard views. With some experience, gross abnormalities that may significantly alter management (eg, flail leaflet, prolapse, large vegetation, chordae rupture) can be detected on visual examination and color Doppler. Dynamic left ventricular outflow tract obstruc-
B lines may help guide diuresis and assess fluid tolerance 
TABLE 5

Estimates of central venous pressure based on inferior vena cava size and collapsibility

Inferior vena cava size

Percent collapse

Estimated central venous pressure

\begin{tabular}{lll}
\hline$\leq 2.1 \mathrm{~cm}$ & $>50 \%$ & $3 \mathrm{~mm} \mathrm{Hg}$ \\
$\leq 2.1 \mathrm{~cm}$ & $<50 \%$ & $8 \mathrm{~mm} \mathrm{Hg}$ \\
$>2.1 \mathrm{~cm}$ & $>50 \%$ & $8 \mathrm{~mm} \mathrm{Hg}$ \\
$>2.1 \mathrm{~cm}$ & $<50 \%$ & $15 \mathrm{~mm} \mathrm{Hg}$
\end{tabular}

tion due to systolic anterior motion of the mitral valve can be detected visually and by using motion mode ( $\mathrm{M}$ mode). Although systolic anterior motion is classically seen with hypertrophic cardiomyopathy, it may also occur in other situations that lead to worsening hemodynamics (eg, sepsis, acute hemorrhage, dehydration). Systolic anterior motion may be associated with severe mitral regurgitation, which resolves with resolution of systolic anterior motion.

However, bedside echocardiography is limited for assessing valvular pathologies. A detailed assessment of valvular lesions (espe-

Lung ultrasonography is $94 \%$ sensitive and $98 \%$ specific for detecting pleural effusion cially stenotic lesions) involves use of spectral Doppler in multiple views, which is not part of basic cardiac ultrasonography. Hence, a comprehensive echocardiographic examination should be considered for evaluating valvular abnormalities and pathology. ${ }^{34}$

\section{Estimating right atrial pressure}

In spontaneously breathing patients, right atrial pressure can be estimated by measuring inferior vena cava size and collapsibility with deep inspiration or "sniff" (Table 5). ${ }^{35}$ The influence of respiratory effort, intra-abdominal pressure, and positive-pressure ventilation may limit the accuracy of the measurement and should be considered. Additionally, the long-axis view of the inferior vena cava is prone to error due to off-plane assessment and respirophasic movement. This can be overcome by acquiring a short-axis (transverse) view. ${ }^{36}$

\section{Evaluating pericardial effusion and tamponade}

Focused cardiac ultrasonography has excellent sensitivity (96\%) and specificity (98\%) for detecting pericardial effusion (PLR 48, NLR 0.04$)^{37}$ and can trigger further consultation for evaluation of tamponade, if clinically suspected (Video 5, Table 4). Hemodynamic instability from cardiac tamponade results from increased pericardial pressure, impairing venous return. The rate of fluid accumulation plays a more prominent role than size in tamponade physiology. Thus, a large volume of pericardial effusion can accumulate over time without impairing hemodynamics, while a smaller pericardial effusion or hemorrhage in the setting of trauma or postprocedure can lead to the need to diligently inspect echocardiographic signs of tamponade.

A plethoric inferior vena cava from impaired filling is highly sensitive (92\%) but not specific for cardiac tamponade. Right atrial collapse for more than one-third of the cardiac cycle is highly sensitive and specific for diagnosing tamponade, followed by right ventricular collapse during diastole. ${ }^{38}$ Absence of chamber collapse has a negative predictive value of $90 \%$. Assessing for tamponade can be difficult, and $\mathrm{M}$ mode may help identify chamber collapse. Concerning or indeterminate findings for tamponade should prompt urgent expert consultation or a confirmatory echocardiogram, or both.

POCUS has been shown to reduce time to pericardiocentesis and is recommended to guide drainage of effusion. ${ }^{39}$

\section{Common pitfalls}

of focused cardiac ultrasonography

Focused cardiac ultrasonography is prone to the following common issues:

Not obtaining a complete echocardiogram when needed. A focused study serves a 


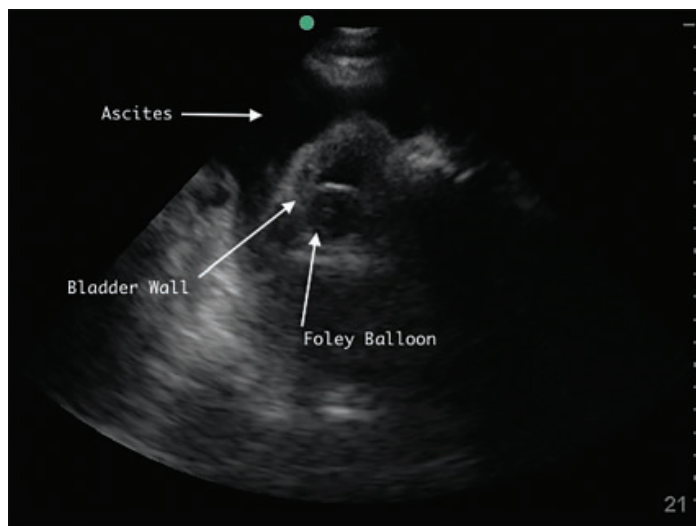

Figure 5. Right lower quadrant with large ascites fluid pocket; Foley catheter in bladder.

different purpose from a complete study and should not replace one. Hence, a "normal" focused cardiac ultrasonographic evaluation does not obviate the need to order a complete transthoracic echocardiogram that is clinically indicated.

Over-relying on POCUS to manage volume. POCUS findings are useful as part of volume status assessment, but a single POCUS finding in isolation should not be used to determine volume management (eg, giving fluids for an apparently "collapsed" inferior vena cava). Findings are prone to variability and must be integrated into overall assessment, not used in isolation.

Delaying POCUS during shock. Focused cardiac ultrasonography should be performed promptly in a patient with shock. Not doing so may lead to an important missed diagnosis, such as pericardial tamponade, ventricular dysfunction, or valvular abnormality.

\section{ABDOMINAL ULTRASONOGRAPHY}

\section{Evaluation of ascites and hemoperitoneum}

Evaluating thoracoabdominal trauma is often a diagnostic challenge, prompting clinicians to depend on ancillary tests to detect potentially life-threatening internal injuries. Ultrasonographic evaluation of free fluid in the abdomen has been extensively studied in trauma literature for detecting hemoperitoneum. Today, ultrasonography has virtually replaced diagnostic peritoneal lavage as a primary, bedside imaging method for trauma patients. ${ }^{40}$ Numerous studies have found that examinations performed and interpreted by

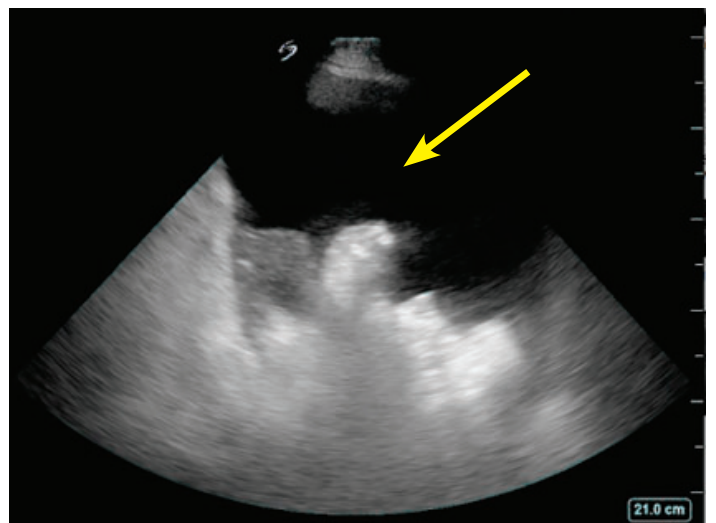

Figure 6. Ascites pocket.

treating physicians are reliably accurate compared with those read by radiologists. ${ }^{41}$

POCUS can also help hospitalists detect ascites. It is more sensitive and specific than physical examination and can guide the decision to perform paracentesis (Figure 5, Figure 6). ${ }^{42}$

\section{Evaluation of kidney and bladder}

Hydronephrosis, a commonly encountered and often reversible cause of acute kidney injury, can be detected with high sensitivity and specificity by a bedside clinician using POCUS (Figure 7). ${ }^{43}$ Hydronephrosis results from urinary flow obstruction, which can be internal (eg, from ureteral calculus or a mass) or external (eg, from ureteral compression from structures such as an enlarged abdominal aortic aneurysm, an advanced pregnancy, or a pelvic mass). Evaluation for hydronephrosis can be useful in cases in which urinary obstruction is considered. This may be particularly important in patients with acute pyelonephritis. However, mimics of hydronephrosis include prominent renal pyramids, prominent renal vasculature, and parapelvic cysts.

Distal obstruction (eg, prostatic hypertrophy) usually results in bilateral hydronephrosis, so it is important to scan both kidneys.

A study found more than $90 \%$ sensitivity and specificity for detecting hydronephrosis by POCUS performed by internal medicine residents given 5 hours of training compared with comprehensive radiologic ultrasonography. ${ }^{44}$

POCUS is also helpful in acute pyelonephritis to evaluate for obstruction. Detecting large obstructive calculi would prompt urgent
Hydronephrosis can be detected with high sensitivity and specificity with POCUS 


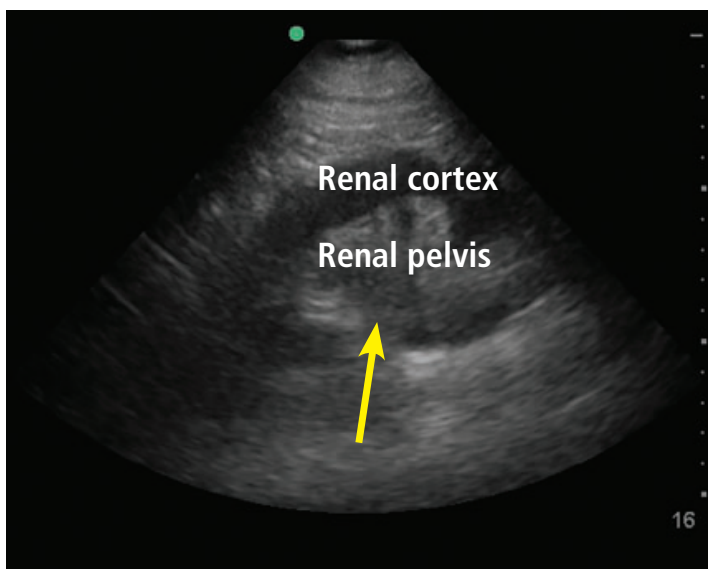

Figure 7. Hydronephrosis. Hypoechoic (dark) fluid (arrow) is shown extending into the renal pelvis.

urologic consultation.

A distended bladder, being a large fluidfilled structure, is easily visualized by ultrasonography and can be distinguished from ascitic fluid. POCUS can be used to estimate bladder volume and confirm proper placement of a urinary catheter by visualizing a Foley balloon inside the bladder (Figure 5). This application may be particularly useful in a patient with obesity or ascites, which can make physical examination or bladder scanner determinations inaccurate. In patients without a urinary catheter, bladder volume estimation should be performed post-void.

can be assessed with POCUS with good specificity

\section{Ultrasound evaluation of the biliary system}

Gallstones appear by ultrasonography as round hyperechoic structures in the gallbladder or bile ducts, with posterior acoustic shadowing. POCUS has demonstrated excellent sensitivity $(89.8 \%)$ and specificity $(88.0 \%)$ for detecting cholelithiasis (PLR 7.48, NLR 0.12). ${ }^{45}$ Findings suggestive of acute cholecystitis include gallstones, pericholecystic fluid, gallbladder wall thickening, and sonographic Murphy sign (ie, abdominal pain elicited by probe pressure), all of which can be assessed at the bedside with good specificity (Figure 8). ${ }^{46}$

The common bile duct can also be measured by POCUS, although it is technically challenging, especially for a novice user. ${ }^{47}$ Requesting a formal ultrasonographic study is prudent to obtain this information.

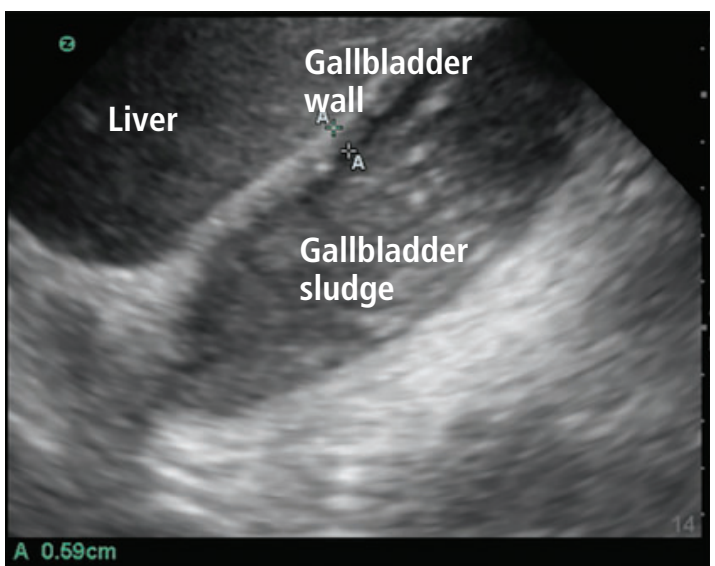

Figure 8. Gallbladder containing sludge, with a thickened anterior wall, in a patient with acute cholecystitis.

\section{EVALUATION OF LOWER-EXTREMITY DEEP VEIN THROMBOSIS}

Although complete duplex ultrasonography is the standard radiological study traditionally performed to evaluate for deep vein thrombosis (DVT), point-of-care compression ultrasonography can be performed rapidly with high diagnostic accuracy after limited training (Figure 9). ${ }^{48}$ A multicenter study of hospitalist-performed compression ultrasonography found a sensitivity of $100 \%$ and specificity of 96\% for identifying lower extremity DVT, reducing the time to diagnosis by nearly 5 hours compared with corresponding vascular studies interpreted by radiologists. ${ }^{49}$ Meta-analyses have also reported sensitivity and specificity higher than $90 \%$ (Table 6). ${ }^{50-52}$ However, inadequate compression, lymph nodes, Baker cysts, and superficial venous thrombosis may be mistaken for a DVT.

A focused DVT study is performed using a high-frequency $(5-12 \mathrm{MHz}$ ) linear probe with compression of the vein at multiple sites, traditionally using a 2-point (common femoral vein and popliteal vein) or 3-point (same, plus superficial femoral vein) method. The 3 -point examination demonstrated higher sensitivity (91\% vs $83 \%$ ) and similar specificity (96\%) to the 2-point examination, but it still can miss $5 \%$ of isolated femoral vein DVTs. ${ }^{53}$ An extended compression examination employing compressing the femoral vein every 2 to 3 $\mathrm{cm}$ until it dives into the adductor canal and popliteal vein along its course is more com- 


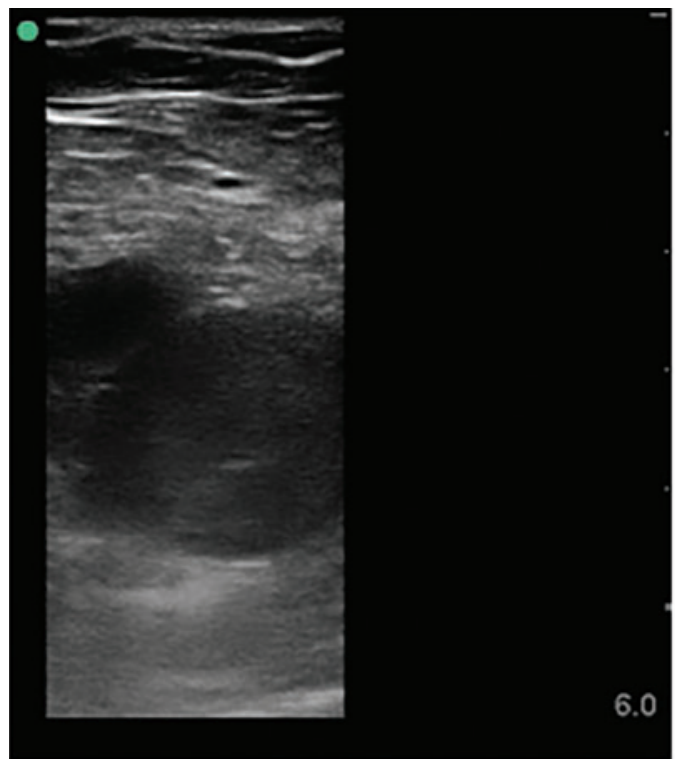

With applied compression of probe

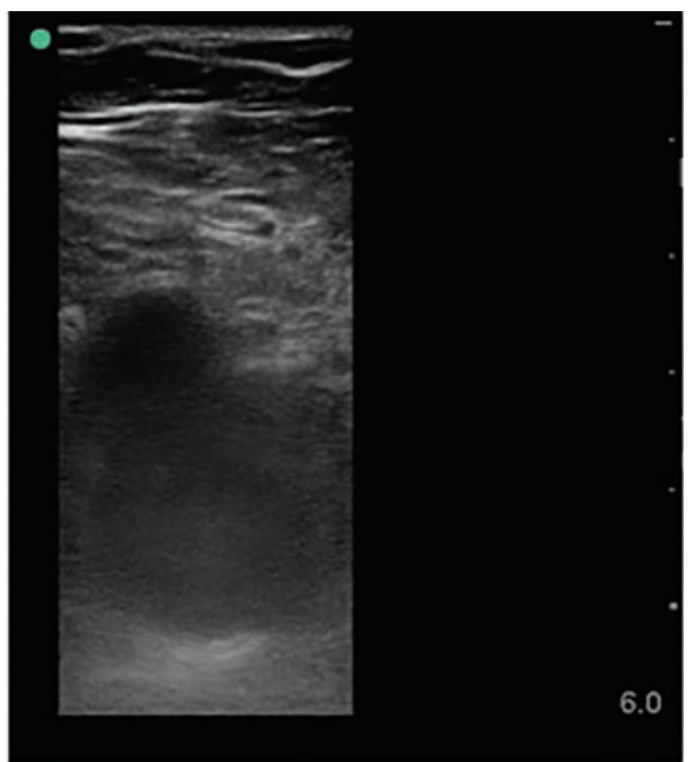

Without applied compression of probe

Figure 9. Right common femoral vein deep vein thrombosis. The left image shows lack of compression of the vein with applied compression of the probe. The right image shows vein without compression.

prehensive and is currently the recommended method. ${ }^{3}$

Duplication of the venous system in the lower extremity is common, and the presence of a DVT in duplicated systems could easily be missed. ${ }^{54}$ A positive POCUS examination may prompt early initiation of anticoagulation and ordering of confirmatory imaging; a negative POCUS test in a patient with high pretest probability needs a comprehensive vascular study. The negative predictive value for a POCUS DVT study is not sufficient to effectively rule out DVT in such patients.

\section{EVALUATING SKIN AND SOFT-TISSUE INFECTIONS}

The major role of POCUS in evaluating skin and soft-tissue infection is to detect abscess formation in the soft tissue. It has been found to change management in more than half of patients presenting with a skin or soft-tissue infection. ${ }^{55}$

The cobblestone appearance of cellulitis (Figure 10) is nonspecific and can be seen in any cause of subcutaneous edema, while ultrasonography is $98 \%$ sensitive and $88 \%$ specific for abscess detection (PLR 8.17, NLR 0.02)..$^{56}$
The appearance of abscesses ranges from anechoic to hyperechoic and may demonstrate posterior acoustic enhancement.

Color Doppler is highly informative, as abscess cavities do not have internal Doppler flow. The presence of flow within the cavity may suggest a vascular structure such as a pseudoaneurysm. Air within the cavity, suggestive of high-grade infection, can be easily detected with ultrasonography.

Ultrasonography may also help diagnose necrotizing fasciitis by detecting fascial and subcutaneous thickening, abnormal fluid accumulation in the deep fascia layer, and subcutaneous air. However, ultrasonography should not be used to rule out the diagnosis of necrotizing fasciitis.

\section{ULTRASONOGRAPHY}

\section{FOR PROCEDURAL GUIDANCE}

Numerous procedures common to hospital medicine practice may be performed more safely and effectively with ultrasonography. The Society of Hospital Medicine has published recommendations for the use of ultrasonography in common hospital medicine procedures, including abdominal paracentesis, ${ }^{42}$ thoracentesis, ${ }^{57}$ lumbar puncture, ${ }^{58}$ and
The major role of POCUS in evaluating skin and soft-tissue infection is to detect abscess formation in soft tissue 
TABLE 6

Meta-analyses evaluating point-of-care ultrasonography for diagnosing deep vein thrombosis

\begin{tabular}{|c|c|c|c|c|c|c|c|c|}
\hline Meta-analysis & $\begin{array}{l}\text { No. of } \\
\text { studies }\end{array}$ & $\begin{array}{l}\text { No. of } \\
\text { patients }\end{array}$ & $\begin{array}{l}\text { Pooled } \\
\text { sensitiv- } \\
\text { ity }\end{array}$ & $\begin{array}{l}95 \% \\
\text { confidence } \\
\text { interval }\end{array}$ & $\begin{array}{l}\text { Pooled } \\
\text { specificity }\end{array}$ & $\begin{array}{l}95 \% \\
\text { confidence } \\
\text { interval }\end{array}$ & $\begin{array}{l}\text { Positive } \\
\text { likelihood } \\
\text { ratio }\end{array}$ & $\begin{array}{l}\text { Negative } \\
\text { likelihood } \\
\text { ratio }\end{array}$ \\
\hline $\begin{array}{l}\text { Burnside et al, }{ }^{50} \\
2008\end{array}$ & 6 & 936 & $95 \%$ & $87 \%-99 \%$ & $96 \%$ & $87 \%-99 \%$ & 23.75 & 0.05 \\
\hline $\begin{array}{l}\text { Pomero et al, }{ }^{51} \\
2013\end{array}$ & 16 & 2,379 & $96.1 \%$ & $90.6 \%-98.5 \%$ & $96.8 \%$ & $94.6 \%-98.1 \%$ & 30.03 & 0.04 \\
\hline West et al, ${ }_{1}^{52} 2015$ & 13 & 1,806 & $96.5 \%$ & $90.1 \%-98.8 \%$ & $96.8 \%$ & $94.7 \%-98.0 \%$ & 30.16 & 0.04 \\
\hline
\end{tabular}

venous access, ${ }^{59}$ as well as for procedural credentialing. ${ }^{60}$

Procedures may be "ultrasound-assisted" or "static" (ie, ultrasonography is used for site selection, then the procedure is performed without ultrasonography) vs "ultrasound-guided" or "dynamic" (ie, the procedure is performed with live ultrasonographic guidance, with the ultrasound probe in one hand and a needle in the other).

\section{Central venous catheter insertion}

For central venous catheter insertion, ultrasonography reduces time to completion and de-

Many predict that POCUS

will be the standard of care in the near future crease failed attempts, with fewer complications like pneumothorax and arterial punctures. It also aids in preprocedural detection of stenosis and thrombosis of the target vein, and it is currently the standard of care for upper-extremity central venous catheter insertion. ${ }^{61}$ Nonetheless, this procedure remains highly user-dependent, and adequate training is critical. ${ }^{62}$

\section{Peripheral intravenous catheter insertion}

Ultrasonography is increasingly used to guide peripheral intravenous catheter insertion. In addition to increasing patient satisfaction, it has demonstrated a higher success rate, particularly in patients with difficult access, reducing the need for a central venous catheter. Ultrasonography can also be used to confirm the correct placement by visualizing the catheter in the vein or detecting bubbles with saline flush. ${ }^{63}$

\section{Abdominal paracentesis}

Ultrasonographic guidance of paracentesis has been found to have a $95 \%$ success rate compared with $61 \%$ using the traditional landmarkbased method. ${ }^{64}$ Unsurprisingly, paracentesis was successfully completed with ultrasonogra- phy in $87 \%$ of the patients for whom the landmark method failed. In a large observational database study of 70,000 patients undergoing paracentesis, ultrasonographic guidance significantly reduced bleeding complications. .5,66 $^{65}$

In addition, a linear probe can help identify underlying vasculature, including the inferior epigastric artery, further minimizing major bleeding risk.

\section{Thoracentesis}

Ultrasonography has also demonstrated a higher rate of success and fewer complications for thoracentesis. In a meta-analysis of 24 studies with 6,605 thoracentesis procedures, ultrasonography significantly reduced pneumothorax compared with the landmark technique, even with inexperienced operators. ${ }^{67}$ The procedure can be performed using static or dynamic ultrasonographic guidance. If static technique is used, the patient position needs to be maintained after marking the spot.

Evaluation of normal lung sliding preprocedure and postprocedure obviates the need for chest radiographs to rule out pneumothorax. ${ }^{57}$

\section{Common pitfalls}

Ultrasound gel can prevent effective preprocedural aseptic skin preparation and postprocedural dressing adherence. Gel should dry before cleaning the skin or applying a dressing.

In addition, use of ultrasonography may sometimes lead to failure to look at anatomical landmarks, leading to performing a procedure at a nonideal site. Users should be mindful of anatomic landmarks in addition to sonographic features. 


\section{CONCLUSION}

The role of bedside ultrasonography has undergone a paradigm shift, with a variety of applications being explored. This shift has been driven by the realization that performance of POCUS is a readily achievable skill and is rewarding in daily practice. It is no surprise that many predict that it will be the standard of care in the near future. Hospitalists are at the forefront of patient care and should be cognizant of the many benefits of POCUS. We hope that wider utilization of ultrasonography at the bedside can improve medical decision-making, translating to better patient care.

\section{DISCLOSURES}

The authors report no relevant financial relationships which, in the context of their contributions, could be perceived as a potential conflict of interest.

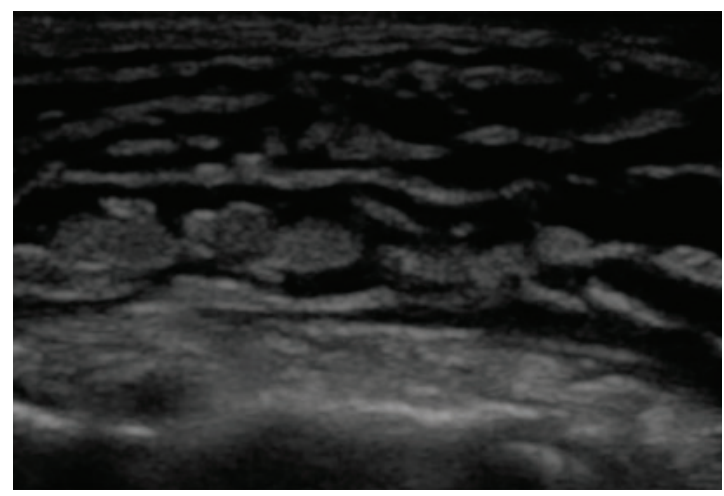

Figure 10. On ultrasonography, subcutaneous fluid is demonstrated as hypoechoic or anechoic (dark) layering within islands of subcutaneous tissue (gray). This occurs in any process leading to fluid within the subcutaneous tissue, including cellulitis and hydrostatic edema.

\section{REFERENCES}

1. Howard ZD, Noble VE, Marill KA, et al. Bedside ultrasound maximizes patient satisfaction. J Emerg Med 2014; 46(1):46-53. doi:10.1016/j.jemermed.2013.05.044

2. Fox S, Dugar S. Point-of-care ultrasound and COVID-19. Cleve Clin J Med 2020 May 14. doi:10.3949/ccjm.87a.ccc019

3. Soni NJ, Schnobrich D, Mathews BK, et al. Point-of-care ultrasound for hospitalists: a position statement of the Society of Hospital Medicine. J Hosp Med 2019; 14:E1-E6. doi:10.12788/jhm.3079

4. Soni NJ, Tierney DM, Jensen TP, Lucas BP. Certification of pointof-care ultrasound competency. J Hosp Med 2017; 12(9):775-776. doi:10.12788/jhm.2812

5. American College of Physicians. ACP statement in support of point of-care ultrasound in internal medicine. Accessed April 20, 2021 https://www.acponline.org/meetings-courses/focused-topics/pointof-care-ultrasound-pocus-for-internal-medicine/acp-statement-insupport-of-point-of-care-ultrasound-in-internal-medicine.

6. PSNet. "The ultrasound looked fine": point-of-care ultrasound and patient safety. Accessed April 20, 2021. https://www.psnet.ahrq.gov/ web-mm/ultrasound-looked-fine-point-care-ultrasound-and-patientsafety.

7. Blaivas M, Pawl R. Analysis of lawsuits filed against emergency physicians for point-of-care emergency ultrasound examination performance and interpretation over a 20-year period. Am J Emerg Med 2012; 30(2):338-341. doi:10.1016/j.ajem.2010.12.016

8. Alrajab S, Youssef AM, Akkus NI, Caldito G. Pleural ultrasonography versus chest radiography for the diagnosis of pneumothorax: review of the literature and meta-analysis. Crit Care 2013; 17(5):R208. doi:10.1186/cc13016

9. Maw AM, Hassanin A, Ho PM, et al. Diagnostic accuracy of pointof-care lung ultrasonography and chest radiography in adults with symptoms suggestive of acute decompensated heart failure: a systematic review and meta-analysis. JAMA Netw Open 2019; 2(3):e190703. doi:10.1001/jamanetworkopen.2019.0703

10. Alzahrani SA, Al-Salamah MA, Al-Madani WH, Elbarbary MA. Systematic review and meta-analysis for the use of ultrasound versus radiology in diagnosing of pneumonia. Crit Ultrasound J 2017; 9(1):6. doi:10.1186/s13089-017-0059-y

11. Yousefifard M, Baikpour M, Ghelichkhani P, et al. Screening performance characteristic of ultrasonography and radiography in detection of pleural effusion: a meta-analysis. Emerg (Tehran) 2016 4(1):1-10. pmid:26862542

12. Laursen $\mathrm{CB}$, Sloth $\mathrm{E}$, Lassen $\mathrm{AT}$, et al. Point-of-care ultrasonography in patients admitted with respiratory symptoms: a single-blind, randomised controlled trial. Lancet Respir Med 2014; 2(8):638-646. doi:10.1016/S2213-2600(14)70135-3

13. Rouby JJ, Arbelot C, Gao Y, et al. Training for lung ultrasound score measurement in critically ill patients. Am J Respir Crit Care Med 2018; 198(3):398-401. doi:10.1164/rccm.201802-0227LE

14. Pivetta E, Goffi A, Lupia E, et al. Lung ultrasound-implemented diagnosis of acute decompensated heart failure in the ED: a SIMEU multicenter study. Chest 2015; 148(1):202-210. doi:10.1378/chest.14-2608

15. Lichtenstein DA. Whole Body Ultrasonography in the Critically III. Berlin Heidelberg: Springer-Verlag; 2010

16. Husain LF, Hagopian L, Wayman D, Baker WE, Carmody KA. Sonographic diagnosis of pneumothorax. J Emerg Trauma Shock 2012; 5(1):76-81. doi:10.4103/0974-2700.93116

17. Lichtenstein D, Mezière G, Biderman P, Gepner A. The "lung point": an ultrasound sign specific to pneumothorax. Intensive Care Med 2000; 26(10):1434-1440. doi:10.1007/s001340000627

18. Lichtenstein $D$, Mezière $G$. A lung ultrasound sign allowing bedside distinction between pulmonary edema and COPD: the comet-tail artifact. Intensive Care Med 1998; 24(12):1331-1334. doi:10.1007/s001340050771

19. Soldati G, Copetti R, Sher S. Sonographic interstitial syndrome: the sound of lung water. J Ultrasound Med 2009; 28(2):163-174 doi:10.7863/jum.2009.28.2.163

20. Volpicelli G, Mussa A, Garofalo G, et al. Bedside lung ultrasound in the assessment of alveolar-interstitial syndrome. Am J Emerg Med 2006; 24(6):689-696. doi:10.1016/j.ajem.2006.02.013

21. Wang Y, Shen Z, Lu X, Zhen Y, Li H. Sensitivity and specificity of ultrasound for the diagnosis of acute pulmonary edema: a systematic review and meta-analysis. Med Ultrason 2018; 1(1):32-36. doi:10.11152/mu-1223

22. Prosen G, Klemen P, Štrnad M, Grmec S. Combination of lung ultrasound (a comet-tail sign) and $\mathrm{N}$-terminal pro-brain natriuretic peptide in differentiating acute heart failure from chronic obstructive pulmonary disease and asthma as cause of acute dyspnea in prehospital emergency setting. Crit Care 2011; 15(2):R114. doi:10.1186/cc10140 
23. Xie HQ, Zhang WW, Sun $\mathbf{S}$, et al. A simplified lung ultrasound for the diagnosis of interstitial lung disease in connective tissue disease: a meta-analysis. Arthritis Res Ther 2019; 21(1):93. doi:10.1186/s13075-019-1888-9

24. Lo Giudice V, Bruni A, Corcioni E, Corcioni B. Ultrasound in the evaluation of interstitial pneumonia. J Ultrasound 2008; 11(1):3038. doi:10.1016/j.jus.2007.10.002

25. Dietrich CF, Mathis G, Blaivas M, et al. Lung B-line artefacts and their use. J Thorac Dis 2016; 8(6):1356-1365. doi:10.21037/jtd.2016.04.55

26. Lichtenstein DA, Lascols N, Mezière G, Gepner A. Ultrasound diag nosis of alveolar consolidation in the critically ill. Intensive Care Med 2004; 30(2):276-281. doi:10.1007/s00134-003-2075-6

27. Kitazono MT, Lau CT, Parada AN, Renjen P, Miller WT Jr. Differentiation of pleural effusions from parenchymal opacities: accuracy of bedside chest radiography. AJR Am J Roentgenol 2010; 194(2):407412. doi:10.2214/AJR.09.2950

28. Ibitoye BO, Idowu BM, Ogunrombi AB, Afolabi BI. Ultrasonographic quantification of pleural effusion: comparison of four formulae. Ultrasonography 2018; 37(3):254-260. doi:10.14366/usg.17050

29. Lucas BP, Candotti C, Margeta B, et al. Diagnostic accuracy of hospitalist-performed hand-carried ultrasound echocardiography after a brief training program. J Hosp Med 2009; 4(6):340-349. doi:10.1002/jhm.438

30. Gudmundsson P, Rydberg E, Winter R, Willenheimer R. Visually estimated left ventricular ejection fraction by echocardiography is closely correlated with formal quantitative methods. Int J Cardiol 2005; 101(2):209-212. doi:10.1016/j.ijcard.2004.03.027

31. Melamed R, Sprenkle MD, Ulstad VK, Herzog CA, Leatherman JW Assessment of left ventricular function by intensivists using handheld echocardiography. Chest 2009; 135(6):1416-1420. doi:10.1378/chest.08-2440

32. Breitkreutz R, Price S, Steiger HV, et al. Focused echocardiographic evaluation in life support and periresuscitation of emergency patients: a prospective trial. Resuscitation 2010; 81(11):1527-1533. doi:10.1016/j.resuscitation.2010.07.013

33. Casazza F, Bongarzoni A, Capozi A, Agostoni O. Regional right ventricular dysfunction in acute pulmonary embolism and right ventricular infarction. Eur J Echocardiogr 2005; 6(1):11-14. doi:10.1016/j.euje.2004.06.002

34. Chamsi-Pasha MA, Sengupta PP, Zoghbi WA. Handheld echocardiography: current state and future perspectives. Circulation 2017; 136(22):2178-2188. doi:10.1161/CIRCULATIONAHA.117.026622

35. Rudski LG, Lai WW, Afilalo J, et al. Guidelines for the echocardiographic assessment of the right heart in adults: a report from the American Society of Echocardiography endorsed by the European Association of Echocardiography, a registered branch of the Euro pean Society of Cardiology, and the Canadian Society of Echocardiography. J Am Soc Echocardiogr 2010; 23(7):685-788. doi:10.1016/j.echo.2010.05.010

36. Schmidt GA. POINT: should acute fluid resuscitation be guided primarily by inferior vena cava ultrasound for patients in shock? Yes. Chest 2017; 151(3):531-532. doi:10.1016/j.chest.2016.11.021

37. Mandavia DP, Hoffner RJ, Mahaney K, Henderson SO. Bedside echocardiography by emergency physicians. Ann Emerg Med 2001; 38(4):377-382. doi:10.1067/mem.2001.118224

38. Klein AL, Abbara S, Agler DA, et al. American Society of Echocardiography clinical recommendations for multimodality cardiovascular imaging of patients with pericardial disease: endorsed by the Society for Cardiovascular Magnetic Resonance and Society of Cardiovascular Computed Tomography. J Am Soc Echocardiogr 2013; 26(9):965-1012.e15. doi:10.1016/j.echo.2013.06.023

39. Alpert EA, Amit U, Guranda L, Mahagna R, Grossman SA, Bentancur A. Emergency department point-of-care ultrasonography improves time to pericardiocentesis for clinically significant effusions. Clin Exp Emerg Med 2017; 4(3):128-132. doi:10.15441/ceem.16.169

40. Savatmongkorngul S, Wongwaisayawan S, Kaewlai R. Focused assessment with sonography for trauma: current perspectives. Open Access Emerg Med 2017; 9:57-62. doi:10.2147/OAEM.S120145
41. Bhoi S, Sinha TP, Ramchandani R, Kurrey L, Galwankar S. To determine the accuracy of focused assessment with sonography for trauma done by nonradiologists and its comparative analysis with radiologists in emergency department of a level 1 trauma center of India. J Emerg Trauma Shock 2013; 6(1):42-46. doi:10.4103/0974-2700.106324

42. Cho J, Jensen TP, Reierson $\mathrm{K}$, et al. Recommendations on the use of ultrasound guidance for adult abdominal paracentesis: a position statement of the Society of Hospital Medicine. J Hosp Med 2019; 14:E7-E15. doi:10.12788/jhm.3095

43. Wong C, Teitge B, Ross M, Young P, Robertson HL, Lang E. The accuracy and prognostic value of point-of-care ultrasound for nephrolithiasis in the emergency department: a systematic review and meta-analysis. Acad Emerg Med 2018; 25(6):684-698. doi:10.1111/acem.13388

44. Caronia J, Panagopoulos G, Devita M, et al. Focused renal sonography performed and interpreted by internal medicine residents. J Ultrasound Med 2013; 32(11):2007-2012. doi:10.7863/ultra.32.11.2007

45. Ross M, Brown M, McLaughlin K, et al. Emergency physician-performed ultrasound to diagnose cholelithiasis: a systematic review. Acad Emerg Med 2011; 18(3):227-235. doi:10.1111/j.1553-2712.2011.01012.x

46. Hilsden R, Leeper R, Koichopolos J, et al. Point-of-care biliary ultrasound in the emergency department (BUSED): implications for surgical referral and emergency department wait times. Trauma Surg Acute Care Open 2018; 3(1):e000164. doi:10.1136/tsaco-2018-000164

47. Lahham S, Becker BA, Gari A, et al. Utility of common bile duct measurement in ED point of care ultrasound: a prospective study. Am J Emerg Med 2018; 36(6):962-966. doi:10.1016/j.ajem.2017.10.064

48. Kory PD, Pellecchia CM, Shiloh AL, Mayo PH, DiBello C, Koenig S. Accuracy of ultrasonography performed by critical care physicians for the diagnosis of DVT. Chest 2011; 139(3):538-542. doi:10.1378/chest.10-1479

49. Fischer EA, Kinnear B, Sall D, et al. Hospitalist-operated compression ultrasonography: a point-of-care ultrasound study (HOCUS-POCUS). J Gen Intern Med 2019; 34(10):2062-2067. doi:10.1007/s11606-019-05120-5

50. Burnside PR, Brown MD, Kline JA. Systematic review of emergency physician-performed ultrasonography for lower-extremity deep vein thrombosis. Acad Emerg Med 2008; 15(6):493-498. doi:10.1111/j.1553-2712.2008.00101.x

51. Pomero F, Dentali F, Borretta V, et al. Accuracy of emergency physician-performed ultrasonography in the diagnosis of deep-vein thrombosis: a systematic review and meta-analysis. Thromb Haemost 2013; 109(1):137-145. doi:10.1160/TH12-07-0473

52. West JR, Shannon AW, Chilstrom ML. What is the accuracy of emergency physician-performed ultrasonography for deep venous thrombosis? Ann Emerg Med 2015; 65(6):699-701. doi:10.1016/j.annemergmed.2014.06.025

53. Adhikari S, Zeger W, Thom C, Fields JM. Isolated deep venous thrombosis: implications for 2-point compression ultrasonography of the lower extremity. Ann Emerg Med 2015; 66(3):262-266. doi:10.1016/j.annemergmed.2014.10.032

54. Zitek T, Baydoun J, Yepez S, Forred W, Slattery DE. Mistakes and pitfalls associated with two-point compression ultrasound for deep vein thrombosis. West J Emerg Med 2016; 17(2):201-208. doi:10.5811/westjem.2016.1.29335

55. Tayal VS, Hasan N, Norton HJ, Tomaszewski CA. The effect of softtissue ultrasound on the management of cellulitis in the emergency department. Acad Emerg Med 2006; 13(4):384-388. doi:10.1197/j.aem.2005.11.074

56. Squire BT, Fox JC, Anderson C. ABSCESS: applied bedside sonography for convenient evaluation of superficial soft tissue infections. Acad Emerg Med 2005; 12(7):601-606. doi:10.1197/j.aem.2005.01.016

57. Dancel R, Schnobrich D, Puri N, et al. Recommendations on the use of ultrasound guidance for adult thoracentesis: a position statement of the Society of Hospital Medicine. J Hosp Med 2018; 13(2):126135. doi:10.12788/jhm.2940 


\section{THIND AND COLLEAGUES}

58. Soni NJ, Franco-Sadud R, Kobaidze K, et al. Recommendations on the use of ultrasound guidance for adult lumbar puncture: a position statement of the Society of Hospital Medicine. J Hosp Med 2019; 14(10):591-601. doi:10.12788/jhm.3197

59. Franco-Sadud R, Schnobrich D, Mathews BK, et al. Recommendations on the use of ultrasound guidance for central and peripheral vascular access in adults: a position statement of the Society of Hospital Medicine. J Hosp Med 2019; 14:E1-E22. doi:10.12788/jhm.3287

60. Lucas BP, Tierney DM, Jensen TP, et al. Credentialing of hospitalists in ultrasound-guided bedside procedures: a position statement of the Society of Hospital Medicine. J Hosp Med 2018; 13(2):117-125. doi:10.12788/jhm.2917

61. Lalu MM, Fayad A, Ahmed O, et al. Ultrasound-guided subclavian vein catheterization: a systematic review and meta-analysis. Crit Care Med 2015; 43(7):1498-1507. doi:10.1097/CCM.0000000000000973

62. Blaivas M, Adhikari S. An unseen danger: frequency of posterior vessel wall penetration by needles during attempts to place internal jugular vein central catheters using ultrasound guidance. Crit Care Med 2009; 37(8):2345-2359. doi:10.1097/CCM.0b013e3181a067d4

63. Gottlieb M, Sundaram T, Holladay D, Nakitende D. Ultrasoundguided peripheral intravenous line placement: a narrative review of evidence-based best practices. West J Emerg Med 2017; 18(6):10471054. doi:10.5811/westjem.2017.7.34610

64. Nazeer SR, Dewbre H, Miller AH. Ultrasound-assisted paracentesis performed by emergency physicians vs the traditional technique: a prospective, randomized study. Am J Emerg Med 2005; 23(3):363367. doi:10.1016/j.ajem.2004.11.001

65. Patel PA, Ernst FR, Gunnarsson CL. Evaluation of hospital complications and costs associated with using ultrasound guidance during abdominal paracentesis procedures. J Med Econ 2012; 15(1):1-7. doi:10.3111/13696998.2011.628723

66. Mercaldi CJ, Lanes SF. Ultrasound guidance decreases complications and improves the cost of care among patients undergoing thoracentesis and paracentesis. Chest 2013; 143(2):532-538. doi:10.1378/chest.12-0447

67. Gordon CE, Feller-Kopman D, Balk EM, Smetana GW. Pneumothorax following thoracentesis: a systematic review and meta-analysis. Arch Intern Med 2010; 170(4):332-339. doi:10.1001/archinternmed.2009.548

Address: Guramrinder Singh Thind, MD, Department of Critical Care Medicine, A90, Respiratory Institute, Cleveland Clinic, 9500 Euclid

Avenue, Cleveland, OH 44195; thindg@ccf.org 